\title{
Standard Treatment of $\alpha$-Tocopherol in Alagille Patients with Severe Cholestasis Is Insufficient
}

\author{
ANNE DAVIT-SPRAUL, CLAUDINE COSSON, MARTINE COUTURIER, MICHELLE HADCHOUEL, \\ ALAIN LEGRAND, FRÉDÉRIQUE LEMONNIER, AND PATRICE THEROND \\ INSERM U347 [C.C., M.C., M.H., F.L., P.T.] and Laboratoire de Biochimie1 [A.D.-S., C.C., A.L., P.T.], \\ Hôpital Bicêtre, AP-HP, 94276 Le Kremlin-Bicêtre Cedex, France
}

\begin{tabular}{|c|c|}
\hline \multicolumn{2}{|c|}{ ABSTRACT } \\
\hline $\begin{array}{l}\text { Alpha-tocopherol }(\alpha \text {-T) is the most effective lipid-soluble } \\
\text { antioxidant present in cells. We investigated the efficacy of } \alpha \text {-T } \\
\text { supplements for preventing lipid peroxidation in patients with } \\
\text { Alagille syndrome, according to the severity of cholestasis. } \\
\text { Patients were assigned to two groups on the basis of plasma } \\
\text { bilirubin concentration (group I, bilirubin }<100 \mu \mathrm{M} \text {; group II, } \\
\text { bilirubin }>100 \mu \mathrm{M}) \text {. } \alpha \text {-T concentrations were determined in } \\
\text { plasma, in isolated lipoproteins, and in red blood cell mem- } \\
\text { branes. In both groups of patients, } \alpha \text {-T concentrations in plasma } \\
\text { were similar to those in control subjects, but the distribution of } \\
\alpha \text {-T in lipoproteins was affected by the abnormal lipoprotein } \\
\text { pattern in these patients. The efficacy of } \alpha \text {-T was estimated by } \\
\text { determining the amount of hydroperoxide produced from phos- } \\
\text { phatidylcholine and phosphatidylethanolamine (PE) molecular } \\
\text { species owing to oxidative stress induced by lipoxygenase treat- } \\
\text { ment. The concentrations of phosphatidylcholine molecular spe- } \\
\text { cies and its corresponding hydroperoxides were significantly } \\
\text { higher in both groups of patients. In group I, } \alpha \text {-T and PE } \\
\text { molecular species concentrations were similar to those in control } \\
\text { subjects, but PE hydroperoxide concentrations were higher than }\end{array}$ & $\begin{array}{l}\text { those in the control subjects. In group II, } \alpha \text {-T concentration was } \\
\text { significantly lower and the concentrations of some PE molecular } \\
\text { species and all PE hydroperoxides were lower than those in the } \\
\text { control subjects. In conclusion, erythrocyte membrane } \alpha \text {-T con- } \\
\text { centration was significantly lower only in patients with severe } \\
\text { jaundice, despite } \alpha \text {-T supplementation, raising the question as to } \\
\text { whether the usual treatment was appropriate in this group. } \\
\text { (Pediatr Res 49: 232-236, 2001) } \\
\text { Q-T, } \alpha \text {-tocopherol Abbreviations: } \\
\text { AGS, Alagille syndrome } \\
\text { GPx, glutathione peroxidase } \\
\text { PL, phospholipids } \\
\text { TC, total cholesterol } \\
\text { PC, phosphatidylcholine } \\
\text { PE, phosphatidylethanolamine } \\
\text { PCOOH, hydroperoxides from PC } \\
\text { PEOOH, hydroperoxides from PE } \\
\text { LpX, lipoprotein X }\end{array}$ \\
\hline
\end{tabular}

AGS is the second most common cause of intrahepatic cholestasis in infancy (1). AGS is a multisystem developmental disorder involving the association of paucity of interlobular bile ducts, pulmonary artery stenosis, butterfly-like vertebrae, posterior embryotoxon, and peculiar facies. It has an autosomal dominant mode of transmission (2), and the Jagged 1 gene on chromosome 20p12 has been identified as the gene for AGS $(3,4)$.

Marked cholestasis with malabsorption involving a deficiency of lipid-soluble vitamins begins in the first year of life. The importance of early vitamin E treatment to prevent secondary neurological disturbances has been clearly demonstrated $(5,6)$. The principal biochemical abnormality in this syndrome is far higher cholesterol and PL concentrations than

Received September 7, 1999; accepted July 21, 2000.

Correspondence and reprint requests: Claudine Cosson, INSERM U347, Hôpital Bicêtre, 80, rue du Général Leclerc, 94276 Le Kremlin-Bicêtre Cedex, France. in other forms of cholestasis, mainly during the period of marked jaundice. We previously reported (7) that the abnormal lipoprotein pattern in AGS patients depends on icterus severity. Another feature of this syndrome is the much higher plasma concentration of lipid peroxides than for other forms of cholestasis (8). These high lipid peroxide levels are inversely correlated with the vitamin $\mathrm{E}$ to total lipids ratio, and this ratio has been reported to be below normal values in about a third of AGS patients, despite vitamin E treatment (9). It therefore seems that vitamin E supplementation may be insufficient to prevent free radical attacks on polyunsaturated fatty acid in membrane PL and to maintain membrane integrity in various tissues in these cholestatic children.

We tested this hypothesis by studying $\alpha$-T concentration and PL hydroperoxide production in erythrocyte membranes from patients with AGS. The hydroperoxides produced from the main molecular species of PC and PE were determined using lipoxygenase to induce peroxidation. The results obtained with patients were compared with those for healthy children. 


\section{METHODS}

Patients. Fifteen patients with AGS were studied. The mean age of the patients was $6 \mathrm{y}$ (range 11 mo to $15 \mathrm{y}$ ). All presented with ductular hypoplasia associated with at least two of the following major features of AGS: ocular posterior embryotoxon, peripheral pulmonary stenosis, butterfly-like vertebral arch defects, and peculiar facies. They displayed various degrees of chronic cholestasis. Three patients were jaundice-free, three had moderate jaundice, and nine had severe jaundice (total bilirubin $>100 \mu \mathrm{M}$ ). All patients were given intramuscular injections of vitamin $\mathrm{E}(10 \mathrm{mg} / \mathrm{kg}$ of $\mathrm{dl}-\alpha-\mathrm{T}$ acetate $)$ every 2 wk, with a maximal intramuscular administration of $200 \mathrm{mg}$. For this study, patients were assigned to group I if they had plasma bilirubin levels of $<100 \mu \mathrm{M}$ and to group II if they had plasma bilirubin levels of $>100 \mu \mathrm{M}$. Control samples were obtained from 15 age-matched children with no hepatic disease who were undergoing biologic tests before surgery. Parental consent was obtained for all patients and controls before inclusion. Approval for this study was obtained from the ethical committee of Bicetre Hospital.

Lipid and lipoprotein analysis. Blood was collected in tubes (Becton Dickinson, Rutherford, NJ, U.S.A.) containing EDTA and centrifuged at $4^{\circ} \mathrm{C}$ at low speed. Total lipoproteins were separated from $4 \mathrm{~mL}$ of plasma, adjusted to a density of 1.210 $\mathrm{g} / \mathrm{mL}$ with solid $\mathrm{KBr}$, by ultracentrifugation at $64,5000 \times g$ for $8 \mathrm{~h}$ at $4^{\circ} \mathrm{C}$ in an NVT 90 rotor (Beckman Instruments, Gagny, France). The uppermost fraction $(\mathrm{d}<1.210 \mathrm{~g} / \mathrm{mL})$ was separated into lipoprotein subclasses by single-spin density gradient ultracentrifugation as previously described (7). Lipoprotein fractions were identified on the basis of absorbance profile and density measurement: VLDL-IDL, $\mathrm{d}<1.026 \mathrm{~g} / \mathrm{mL}$; LDL, $1.026<\mathrm{d}<1.063 \mathrm{~g} / \mathrm{mL}$; HDL, $1.063<\mathrm{d}<1.210 \mathrm{~g} / \mathrm{mL}$. In severely icteric patients with LpX, LDL were collected between 1.026 and $1.050 \mathrm{~g} / \mathrm{mL}, \mathrm{LpX}$ between 1.050 and 1.100 $\mathrm{g} / \mathrm{mL}$, and HDL between 1.100 and $1.150 \mathrm{~g} / \mathrm{mL}$. TC and PL concentrations in plasma and lipoproteins were determined enzymatically.

Chromatographic equipment. We used a Thermo Separation Products (Les Ulis, France) HPLC machine equipped with a UV-visible light detector and a fluorometer (Spectroflow 980 fluorescence detector, Applied Biosystems, Ramsey, NJ, U.S.A.).

Reagents and chemicals. HPLC-grade solvents and analytical-grade chemicals were obtained from Carlo Erba (Milan, Italy). Microperoxidase (MP11), isoluminol (6-amino-2,3 dihydro-1,4-phthalazinedione), soybean lipoxygenase (type IB, EC 1.13.11.12), 15-hydroperoxyeicosatetraenoic acid, and 13hydroperoxyoctadecadienoic acid were purchased from Biomol (Tebu, France).

Ghost preparation. Blood was drawn into heparinized Vacutainer tubes and was centrifuged for $10 \mathrm{~min}$ at $1000 \times \mathrm{g}$. The cell pellet was washed three times with isotonic buffer. Erythrocyte ghosts were prepared by lysing packed cells in 7 vol of hypotonic phosphate buffer $(5 \mathrm{mM}, \mathrm{pH}$ 7) containing $1 \mathrm{mM}$ EDTA as described by Burton et al. (10). The ghosts were washed in the same buffer as many times as required to obtain white membranes. They were stored at $-70^{\circ} \mathrm{C}$ until use.
Peroxidation of erythrocyte membranes. About 400 to 600 $\mu \mathrm{g}$ of membrane protein was used for peroxidation. The membrane pellet was suspended in $0.1 \mathrm{M}$ borate buffer, $\mathrm{pH}$ 9.2, containing $10 \mathrm{mM}$ deoxycholic acid (11). The reaction was started by adding lipoxygenase to achieve a final concentration of $50 \mu \mathrm{g} / \mathrm{mL}$. The mixture was incubated at $30^{\circ} \mathrm{C}$ with gentle shaking for $20 \mathrm{~min}$. The reaction was stopped by adding $1 \mathrm{M}$ citric acid to a final $\mathrm{pH}$ of 3.5 , and the samples were placed on ice for $5 \mathrm{~min}$. A sample was incubated in the same conditions in the absence of lipoxygenase to determine the molecular species of PL present before peroxidation.

Lipid extraction and PL separation. Lipids were extracted with chloroform-methanol (2:1, vol/vol). Silica SepPak columns were used to separate PL into PC and PE, using the extraction technique described by Hamilton and Comai (12). The two fractions corresponding to PC and PE were evaporated to dryness, then dissolved in methanol, and injected into the HPLC system.

Detection of PC and PE molecular species and their corresponding hydroperoxides. Compounds were separated on the liquid chromatograph using two serial analytical columns: a C8 $(150 \times 4.6 \mathrm{~mm})$ and a C18 $(250 \times 4.6 \mathrm{~mm})$ Kromasil column, $5 \mu \mathrm{m}$ in diameter, maintained at $40^{\circ} \mathrm{C}$. The mobile

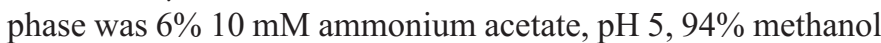
(flow rate, $1.5 \mathrm{~mL} / \mathrm{min}$ ). PC and PE molecular species were detected at $205 \mathrm{~nm}$ before and after $20 \mathrm{~min}$ of peroxidation. The eluate was mixed at a flow rate of $1.5 \mathrm{~mL} / \mathrm{min}$ with the chemiluminescent reagent, prepared as described by Yamamoto et al. (13) with slight modifications. Isoluminol (55 $\mathrm{mg} / \mathrm{L}$ ) was dissolved in $0.1 \mathrm{M}$ borate buffer, $\mathrm{pH} 9.2$, and 10 $\mathrm{mg} / \mathrm{L}$ of microperoxidase was added to the mixture. The solution was passed through a fluorometer used as a photon detector, with the excitation source turned off.

Molecular species and hydroperoxide identification. Fatty acid molecular species from PC and PE were identified by gas-liquid chromatography, using a standard commercial mixture for comparison as previously described (14). The corresponding hydroperoxides were identified by peroxidation of the standard molecular species as previously described (15). Hydroperoxides were quantified on the basis of the relative sensitivity of the chemiluminescence assay for 15-hydroperoxyeicosatetraenoic acid and 13-hydroperoxyoctadecadienoic acid.

$\boldsymbol{\alpha}-\boldsymbol{T}$ and $\boldsymbol{G P x}, \alpha-\mathrm{T}$ was determined using an HPLC technique derived from that of Zaspel and Csallany (16). GPx activity was determined as described by Paglia and Valentine (17), using Triton X-100 to solubilize the membranes.

Statistical analysis. Data are expressed as median value and range. The statistical significance of differences was determined with the Mann-Whitney test. Correlations were analyzed by calculating the linear correlation coefficient.

\section{RESULTS}

Median plasma cholesterol and PL concentrations were significantly higher in the 15 patients studied than in control children (TC, 8.85 versus $4.21 \mathrm{mmol} / \mathrm{L}, p<0.005$; PL, 6.47 versus $2.29 \mathrm{mmol} / \mathrm{L}, p<0.002$ ), despite the wide range of TC 
$(5.08-43.1 \mathrm{mmol} / \mathrm{L})$ and PL $(3.01-34.0 \mathrm{mmol} / \mathrm{L})$ values in patients. The severely icteric children $(n=9$; bilirubin $>100$ $\mu \mathrm{M})$ had a higher median cholesterol value $(27.85 \mathrm{mmol} / \mathrm{L})$ associated with hyperbetalipoproteinemia, hypoalphalipoproteinemia, and, in several cases $(n=6)$, the presence of LpX. In contrast, in mildly icteric patients ( $n=6$; bilirubin $<100 \mu \mathrm{M})$, hypercholesterolemia $(7.77 \mathrm{mmol} / \mathrm{L})$ was associated with hyperalphalipoproteinemia (data not shown).

Vitamin E status, as monitored by plasma vitamin E concentration, did not differ significantly between patients and control children (22.98 versus $25.65 \mu \mathrm{mol} / \mathrm{L})$. However, when expressed as a ratio of plasma vitamin $\mathrm{E}$ to lipids, vitamin $\mathrm{E}$ status was lower in all patients $(1.37 \mu \mathrm{mol} / \mathrm{g})$ than in control children $(5.57 \mu \mathrm{mol} / \mathrm{g})$, owing to the high plasma lipid levels in patients. Patients with severe icterus had the lowest vitamin E to lipids ratio $(0.79 \mu \mathrm{mol} / \mathrm{g})$ compared with those with mild icterus $(2.33 \mu \mathrm{mol} / \mathrm{g})$. The distribution of $\alpha$-T in lipoproteins was very different in each group of patients from that in control subjects and was affected by lipoprotein pattern (Fig. 1). In control subjects, $53.8 \%$ of $\alpha$-T was recovered in the VLDLLDL and $46.2 \%$ in HDL. In mildly icteric patients, $\alpha$-T was mainly transported by HDL (57\%), whereas in severely icteric patients, $\alpha$-T was mainly transported by LDL and LpX (94.9\%) and poorly by HDL (2.4\%).

The 15 patients had significantly higher cholesterol concentrations and GPx activity in erythrocyte membranes (Table 1) and significantly lower $\alpha$-T concentrations than the control children. There was a negative relationship between $\alpha$-T concentration and GPx activity $(r=0.76, p<0.01)$ in the patient group only. We considered the two subgroups (based on plasma bilirubin concentration) separately, and membrane cholesterol concentration was found to be significantly higher than normal in group I (bilirubin $<100 \mu \mathrm{M}$ ) and group II (bilirubin $>100 \mu \mathrm{M})$. However, significant changes in membrane $\alpha$-T concentration and GPx activity were observed only in group II patients (Table 1).

Table 2 shows the concentrations of the main molecular species from $\mathrm{PE}$ and $\mathrm{PC}$ and their corresponding hydroperoxides $(\mathrm{PEOOH}$ and $\mathrm{PCOOH})$ produced after the induction of lipid peroxidation. There was no significant difference in the concentrations of PE molecular species between the 15 patients and the control children. However, when we considered the results in relation to the severity of jaundice, we observed concentrations of PE molecular species 16:0/20:4+22:6 and 16:0/18:2 significantly lower in group II than those of the control children, but not in group I. PEOOH concentrations were similar for the 15 patients and control children, whereas

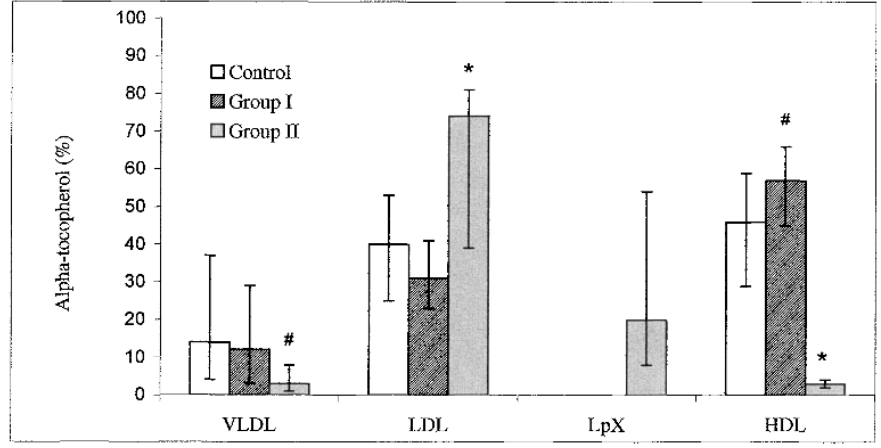

Fig. 1. Distribution of $\alpha-\mathrm{T}$ in plasma lipoproteins from control and AGS patients. $\alpha$-T was measured, using an HPLC procedure, in each lipoprotein fraction isolated by ultracentrifugation. $\alpha$-T content in each lipoprotein fraction (median and range values) is expressed as a percentage of $\alpha$-T concentration in whole plasma. $\# p<0.05 ; * p<0.001$ indicate significant differences between patients and control children.

the two subgroups gave contrasting results. The concentrations of each PEOOH species were significantly higher than normal (except for PE 16:0/18:2) in group I children and significantly lower than normal in group II children. In contrast, we observed significantly higher concentrations of all PC molecular species (approximately double) in both groups of patients compared with the control children. Similarly, the concentrations of hydroperoxides from the various PC molecular species were significantly higher in patients than in control children, and no difference was observed between group I and group II.

\section{DISCUSSION}

The aim of this study was to investigate the efficacy of $\alpha$-T supplementation against oxidative stress in cholestatic patients with AGS. We have previously shown (7) that in these patients, the abnormal lipoprotein pattern depends on icterus severity. Thus, patients were classified as having mild (group I) or severe jaundice (group II). We observed that these abnormal lipoprotein patterns affected the distribution of $\alpha$-T in lipoproteins. We found that $53.8 \%$ of circulating $\alpha$-T was transported by VLDL-LDL in control subjects and $46.2 \%$ by HDL, consistent with the previously reported distribution (18). In contrast, in severely icteric patients, $94.9 \%$ of $\alpha$-T was transported by LDL and LpX whereas HDL contained only $2.4 \%$ of circulating $\alpha$-T. Furthermore, in mildly icteric patients with hyperalphalipoproteinemia, a high proportion of $\alpha-\mathrm{T}(57 \%)$ was transported by HDL. This abnormal distribution of $\alpha$-T in plasma lipoproteins may affect the transfer of $\alpha$-T between lipoproteins and red blood cells. LpX, which incorporates a

Table 1. TC and $\alpha$-T concentrations and GPx activity (median and range) in erythrocyte membranes

\begin{tabular}{|c|c|c|c|c|}
\hline Variable & $\begin{array}{c}\text { Control group } \\
n=15\end{array}$ & $\begin{array}{l}\text { AGS group } \\
n=15\end{array}$ & $\begin{array}{c}\text { Group I } \\
\text { bilirubin }<100 \mu \mathrm{M} \\
n=6\end{array}$ & $\begin{array}{c}\text { Group II } \\
\text { bilirubin }>100 \mu \mathrm{M} \\
n=9\end{array}$ \\
\hline $\mathrm{TC}(\mu \mathrm{mol} / \mathrm{mg}$ protein $)$ & $0.622(0.51-0.80)$ & $0.750 \dagger(0.55-1.22)$ & $0.758 \dagger(0.66-1.22)$ & $0.749 \dagger(0.55-0.85)$ \\
\hline GPx (mU/mg protein) & $22.2(15.8-31.1)$ & $31.8 *(14.0-51.8)$ & $24.9(14.0-45.6)$ & $37.5 \dagger \div(27.4-51.8)$ \\
\hline
\end{tabular}

* Comparison between control and patient groups (statistically different from control, $p<0.01$ ).

$\dagger$ Comparison between control and patient groups (statistically different from control, $p<0.001$ ).

$\ddagger$ Comparison between patients in group I and in group II (statistically different from each other, $p<0.05$ ). 


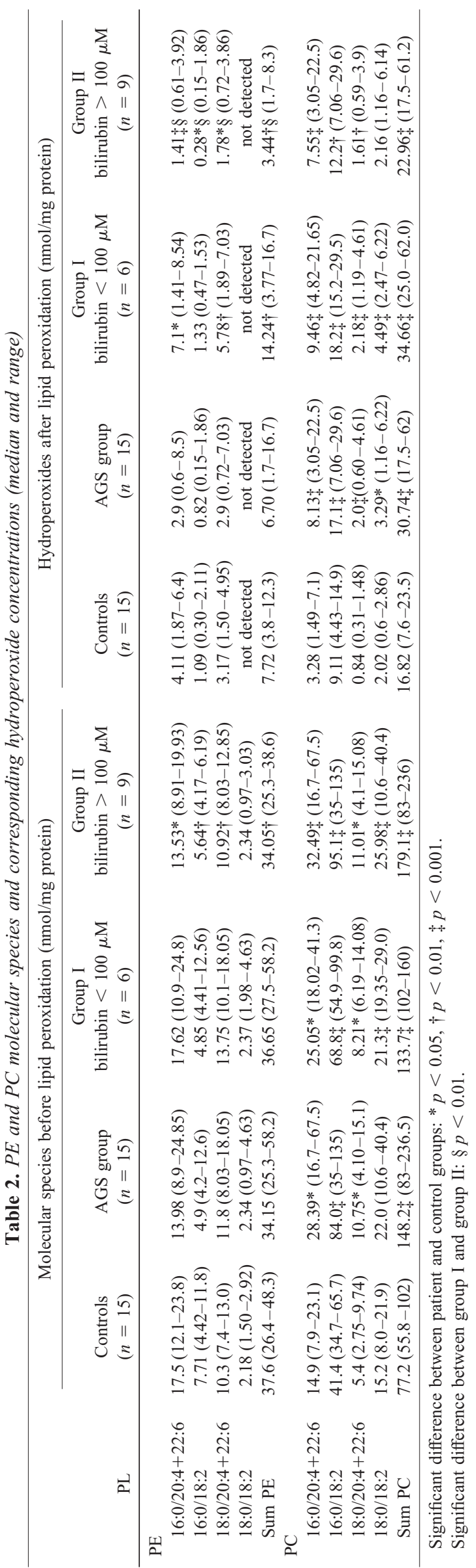

proportion of circulating $\alpha$-T, is probably unable to release it, and HDL, known to be the principal donors of $\alpha$-T to red blood cells $(19,20)$, are present at very low concentration in severely icteric patients. Therefore, $\alpha$-T concentrations in the erythrocyte membranes of patients were affected by plasma lipoprotein pattern, and $\alpha$-T membrane concentrations significantly lower than normal were observed only in the most cholestatic patients (Table 1), who had low HDL-cholesterol concentrations.

The low concentration of $\alpha$-T in group II erythrocyte membranes may also be related to the role of this molecule as an antioxidant in lipid peroxidation. This seems likely because we observed higher levels of GPx activity in the erythrocyte membranes of group II patients than in control children. The higher level of membrane GPx activity, which is specific to PL hydroperoxides, may reflect oxidative stress in vivo, acting as an indirect marker for the overproduction of PL hydroperoxides. However, in our experimental conditions, no hydroperoxide was detected before lipoxygenase treatment. The absence of hydroperoxides may be related to the high level of GPx activity, because GPx transforms PL hydroperoxides into PL alcohols, which cannot be detected in our assay. The inverse relationship between membrane $\alpha$-T concentration and GPx activity observed in this group may simply reflect the complementary effects of these two antioxidant systems.

The markedly higher concentration of membrane PC species in the two subgroups was principally because of the reflux of bile, and particularly of bile lipids in the plasma. PC is the principal PL in bile and accounts for $>95 \%$ of biliary PL in humans (21). An excess of PC in erythrocyte membranes in obstructive jaundice was described many years ago (22). The authors suggested that $\mathrm{LpX}$ containing a high proportion of $\mathrm{PC}$ was responsible for the extensive incorporation of PC into erythrocyte membranes by lipid exchange after fusion between LpX and red blood cell membranes.

The erythrocyte membrane $\mathrm{PCOOH}$ concentrations resulting from lipoxygenase treatment were significantly higher in both subgroups than in the control children. This excess of $\mathrm{PCOOH}$ may be related to the high concentration of PC molecular species in membranes, although no relationship was demonstrated between the concentrations of $\mathrm{PCOOH}$ and $\mathrm{PC}$ molecular species. In contrast, membrane $\mathrm{PEOOH}$ concentrations differed greatly between the two subgroups studied. In patients with mild jaundice (group I), PEOOH concentration was significantly higher than that of the control children, whereas $\alpha$-T concentration was normal. In severely jaundiced patients (group II), both PEOOH and $\alpha$-T concentrations were significantly lower than those in control children. These results are surprising, given the known antioxidant role of $\alpha$-T. The low concentration of several PE molecular species in group II partly accounted for the low PEOOH concentration, but low membrane $\alpha$-T level was expected to be associated with a high hydroperoxide concentration. Our results for group II are consistent with our previous study of erythrocyte membranes from healthy children, in which low $\alpha$-T concentration was associated with low hydroperoxide concentration (14). We have also shown that in vitro $\alpha$-T enrichment of the erythrocyte membranes of cystic fibrosis patients leads to an increase in PL 
hydroperoxide concentration after lipoxygenase treatment (unpublished results). The involvement of $\alpha$-T in the various steps of lipid peroxidation has been put forward as an explanation for these results. As $\alpha$-T acts as a hydrogen donor, it scavenges chain-propagating radicals and eliminates peroxyl radicals, thereby stabilizing the hydroperoxides produced. In the absence of effective hydrogen donors, such as vitamin E, peroxyl radicals increase in concentration and their transformation into hydroperoxides is reduced. The results obtained for group II suggest that a decrease in membrane $\alpha$-T content may cause a marked decrease in the stability of PEOOH. In the patients of group I, normal $\alpha$-T concentration may limit the degradation of $\mathrm{PEOOH}$, and this may partly account for the high $\mathrm{PEOOH}$ concentration observed in this group. However, $\alpha$-T is probably not the only factor involved in the regulation of hydroperoxide production. Other antioxidant systems acting at various stages of lipid peroxidation may also be deficient in the erythrocyte membranes of AGS patients. Erythrocyte $\beta$-carotene concentration is low in various hepatobiliary diseases, and particularly in cholestasis (23). Various studies have shown $(24,25)$ that carotenoids inhibit free radical-induced lipid peroxidation and that $\beta$-carotene is one of the most efficient quenchers of lipid peroxyl radicals.

The main conclusion of this work is that there is an $\alpha$-T deficiency in the erythrocyte membranes of severely icteric patients with AGS, despite $\alpha$-T supplementation, and that this deficiency is a consequence of the abnormal lipoprotein pattern of these patients. The lower hydroperoxide concentrations in the erythrocyte membranes of patients in this group confirm the antioxidant role of $\alpha$-T, which scavenges chain-propagating radicals, and suggest that $\alpha-\mathrm{T}$ is insufficient for efficient protection of cell membranes against lipid peroxidation. These data suggest that the usual $\alpha$-T supplementation (intramuscular administration at a dose of $10 \mathrm{mg} / \mathrm{kg}$ every 2 wk) was inappropriate for severely icteric patients. Increasing the dose of $\alpha$-T supplements by intramuscular administration caused problems because of the frequency and volume of injections required. Thus, oral administration of tocopheryl polyethylene glycol succinate, a water-soluble form of $\alpha$-T, may be a useful alternative therapy for correcting $\alpha$-T deficiency in cholestasis (26) and counteracting oxidative injury. We propose to evaluate this therapeutic strategy in a future study.

Acknowledgments. The authors thank Prof. Olivier Bernard, Pediatric Hepatology, Bicêtre Hospital, 94275 Le KremlinBicêtre, France, for supplying them with plasma samples from the patients and for his interest throughout this investigation.

\section{REFERENCES}

1. Hadchouel M 1992 Paucity of interlobular bile ducts. Semin Diagn Pathol 9:24-30

2. Dhorne-Pollet S, Deleuze JF, Hadchouel M, Bonaiti-Pellié C 1994 Segregation analysis of Alagille syndrome. J Med Genet 31:453-457

3. Li L, Krantz ID, Deng Y, Genin A, Banta AM, Collins CC, Qi M, Trask BJ, Kuo WL, Cochran J, Pierpont MEM, Rand EB, Piccoli DA, Hood L, Spinner NB 1997 Alagille syndrome is caused by mutations in human Jagged1, which encodes a ligand for Notch1. Nat Genet 16:243-250

4. Oda T, Elkahloun AG, Pike BL, Okajima K, Krantz ID, Genin A, Piccoli DA, Meltzer PS, Spinner NB, Collins FS, Chandrasekharappa SC 1997 Mutations in the human Jaggedl gene are responsible for Alagille syndrome. Nat Genet 16:235-242

5. Alvarez F, Landrieu P, Feo C, Lemonnier F, Bernard O, Alagille D 1985 Vitamin E deficiency is responsible for neurologic abnormalities in cholestatic children. J Pediatr 107:422-425

6. Sokol RJ, Guggenheim MA, Iannaccone ST, Barkhaus PE, Miller C, Silverman A, Balistreri WF, Heubi JE 1985 Improved neurologic function after long-term correction of vitamin $\mathrm{E}$ deficiency in children with chronic cholestasis. N Engl J Med 313:1580-1586

7. Davit-Spraul A, Pourci ML, Atger V, Cambillau M, Hadchouel M, Moatti N, Legrand A 1996 Abnormal lipoprotein pattern in patients with Alagille syndrome depends on icterus severity. Gastroenterology 111:1023-1032

8. Lemonnier F, Alvarez F, Babin F, Couturier M, Alagille D 1990 Effects of vitamin E treatment in cholestatic children. Adv Exp Med Biol 264:143-146

9. Babin F, Lemonnier F, Goguelin A, Alagille D, Lemonnier A 1988 Plasma fatty acid composition and lipid peroxide levels in children with paucity of interlobular bile ducts. Ann Nutr Metab 32:220-230

10. Burton GW, Ingold KU, Thompson KE 1981 An improved procedure for isolation of ghost membranes from human red blood cells. Lipids 16:946

11. Brash AR, Ingram CD, Harris TM 1987 Analysis of a specific oxygenation reaction of soybean lipoxygenase-1 with fatty acids esterified in phospholipids. Biochemistry 26:5465-5471

12. Hamilton JG, Comai K 1988 Rapid separation of neutral lipids, free fatty acids and polar lipids using prepacked silica Sep-Pak columns. Lipids 23:1146-1149

13. Yamamoto Y, Brodsky MH, Baker JC, Ames BN 1987 Detection and characterization of lipid hydroperoxides at picomole levels by high-performance liquid chromatography. Anal Biochem 160:7-13

14. Therond P, Couturier M, Demelier JF, Lemonnier F 1996 Hydroperoxides of erythrocyte phospholipid molecular species formed by lipoxygenase correlate with $\alpha$-tocopherol levels. Lipids 31:703-708

15. Therond P, Couturier M, Demelier JF, Lemonnier F 1993 Simultaneous determination of the main molecular species of soybean phosphatidylcholine or phosphatidylethanolamine and their corresponding hydroperoxides obtained by lipoxygenase treatment. Lipids 28:245-249

16. Zaspel BJ, Csallany AS 1983 Determination of alpha-tocopherol in tissues and plasma by high-performance liquid chromatography. Anal Biochem 130:146-150

17. Paglia DE, Valentine WN 1967 Studies on the qualitative characterization of eryth rocyte glutathione peroxidase. J Lab Clin Med 70:158-169

18. Carcelain G, David F, Lepage S, Bonnefont-Rousselot D, Delattre J, Legrand A, Peynet J, Troupel S 1992 Simple method for quantifying $\alpha$-tocopherol in low-density + very-low-density lipoproteins and in high-density lipoproteins. Clin Chem 38:1792-1795

19. Kayden HJ, Bjornson LK 1972 The dynamics of vitamin E transport in the human erythrocyte. Ann NY Acad Sci 203:127-140

20. Morita T, Kitagawa M, Mino M 1989 Tocopherol distribution in serum lipoproteins with respect to red blood cell tocopherol levels in children. J Nutr Sci Vitaminol 35:243-251

21. Hay DW, Carey MC 1990 Chemical species of lipids in bile. Hepatology 12(suppl):6S-16S

22. Okano Y, Yamauchi T, Sekiya T, Iida H, Hasegawa I, Nozawa Y 1978 Mechanism for lipid abnormalities of erythrocyte membranes in biliary obstruction: lecithin content and its fatty acyl composition. Clin Chim Acta 88:237-248

23. Leo MA, Ahmed S, Aleynik SI, Siegel JH, Kasmin F, Lieber CS 1995 Carotenoids and tocopherols in various hepatobiliary conditions. J Hepatol 23:550-556

24. Burton GW 1989 Antioxidant action of carotenoids. J Nutr 119:109-111

25. Tsuchihashi H, Kigoshi M, Iwatsuki M, Niki E 1995 Action of $\beta$-carotene as an antioxidant against lipid peroxidation. Arch Biochem Biophys 323:137-147

26. Sokol RJ, Butler-Simon N, Conner C, Heubi JE, Sinatra FR, Suchy FJ, Heyman MB, Perrault J, Rothbaum RJ, Levy J, Iannaccone ST, Shneider BL, Koch TK, Narkewicz MR 1993 Multicenter trial of d- $\alpha$-Tocopheryl polyethylene glycol 1000 succinate for treatment of vitamin E deficiency in children with chronic cholestasis. Gastroenterology 104:1727-1735 